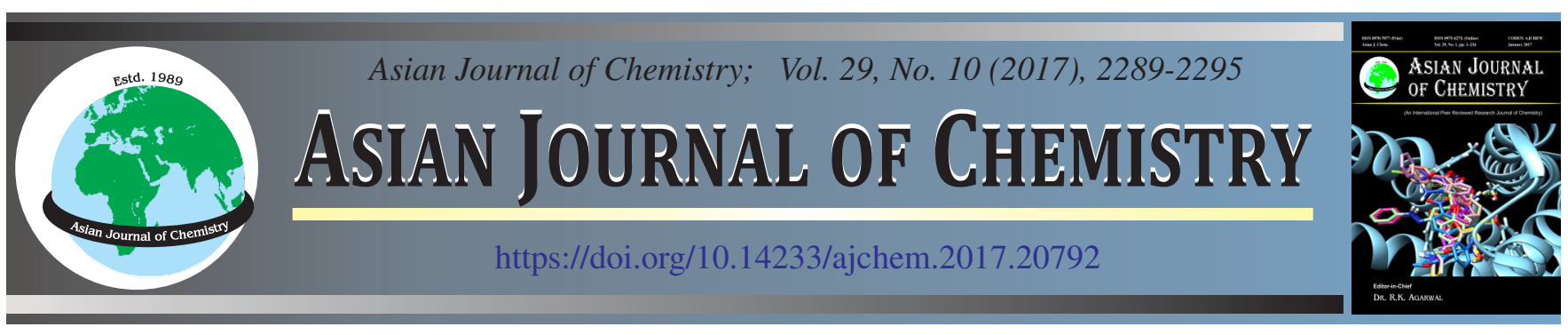

\title{
Distribution and Source Contributions of Polycyclic Aromatic Hydrocarbons in Sediments from Poyang and Longgan Lakes in China
}

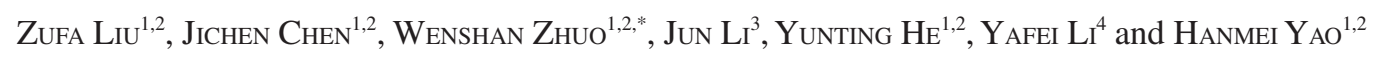

${ }^{1}$ Center for Water Resource and Environment, Sun Yat-sen University, Guangzhou 510275, P.R. China

${ }^{2}$ Key Laboratory of Water Cycle and Water Security in Southern China of Guangdong Higher Education Institutes, Guangzhou 510275, P.R. China

${ }^{3}$ State Key Laboratory of Organic Geochemistry, Guangzhou Institute of Geochemistry, Chinese Academy of Sciences, Guangzhou 510640, P.R. China

${ }^{4}$ Key Laboratory of Terrestrial Water Cycle and Surface Processes, Institute of Geographic Sciences and Natural Resources Research, CAS, Beijing 100101, P.R. China

*Corresponding author: Tel: +86 13450238826; E-mail: zadeozws@ mail.sysu.edu.cn

\begin{abstract}
Concentrations of polycyclic aromatic hydrocarbons (PAHs) were determined in two sediment cores collected form Poyang lake and Longgan lake. Sixteen US-EPA (US-Environmental Protection Agency) priority PAHs analyzed were in the range of 70-6855 ng/g from 1930 to 2011 and 60-231744 ng/g from 1901 to 2011 in Cores PY and LG, respectively. The concentrations and patterns of PAH distribution changing over this period may be related to local economic development. Isomeric ratios reveal that pyrolytic sources were the predominant contributions in both sediment cores; while various cores in mid-depth part were derived mainly from the petrogenic sources. The period from 1943 to 1976 in Core PY and from 1932 to 1982 in Core LG, may be a transition period, along with a mixture of biomass and petroleum combustion sources. According to the toxicological risk evolutions, benzo[a]pyrene (BaP), dibenzo[a,h]anthracene (DahA), and benzo[b]fluoranthene $(\mathrm{BbF})$ were the dominant toxic compositions and benzo[a]pyrene (BaP) which contributed the maximum carcinogenic exposure equivalent was the most hazardous in both two core sediments. The toxic assessment suggested that the PAHs in soils were at low potential of ecotoxicological contamination level.
\end{abstract}

Keywords: Polycyclic aromatic hydrocarbons, Poyang and Longgan lakes, Historical distribution, Risk.

\section{INTRODUCTION}

Polycyclic aromatic hydrocarbons (PAHs), as a typical class of persistent organic pollutants (POPs) made up of two or more fused benzene rings, generally derive from incomplete combustion of organic substances, such as wood, fossil fuels, asphalt and industrial wastes $[1,2]$. When produced, PAHs tend to be diffusely dispersed into the aquatic environment by means of atmospheric transport or stream pathways and eventually be absorbed to sediments as an internal source of pollution [3]. The absorbed PAHs may release back into the water column via biological and chemical processes once the environmental conditions change [4]. Owing to potential carcinogenic, teratogenic and mutagenic effects to humans, 16 PAHs have been listed as priority pollutants by US-EPA (US-Environmental Protection Agency). Research on PAHs concentrations and possible sources in sediments is critical for effective pollution abatement [5]. With continuity, high resolution and affluent available information, undisturbed lake sediment cores are increasingly working to reconstruct the historical trends of PAHs, which are closely related to the changes in energy structure and economic development [6,7]. Most of the previous studies were focus on the vertical distributions of the "PAHs concentrations [8-10], while only few involved source contributions to "PAHs in the dated sediments. Besides, compared with developed countries, very little study was on the temporal trends of PAHs pollution sources in developing countries.

Poyang lake is the largest freshwater lake located in Jiangxi Province in China. It is fed by the Gan, Xin, Rao, Xiu and Fu five major tributaries. Poyang lake basin, with an area of $162200 \mathrm{~km}^{2}$ and a population of more than 15.1 million, collects almost all of industrial and agricultural pollutants of Jiangxi Province. Before the Eastern Han Dynasty, Poyang lake was united with Longgan lake. But now, Longgan lake, also a fresh lake in China, is situated near the north bank of the middle reaches of Yangtze river, opposite Poyang lake. 
With a basin of $5365 \mathrm{~km}^{2}$ and a population of 50 thousand, it is the juncture of Suson County of Anhui Province and Huangmei County of Hubei Province of China. Both Poyang lake and Longgan lake are rich in natural resources and exploitable potentialities, which have been approved as state-level natural protection areas.

\section{EXPERIMENTAL}

Sediment sampling: Sampling sites were chosen in Poyang lake (PY) and Longgan lake (LG) (Fig. 1). During November 2011, two parallel sediment cores (0-40 cm in depth), which were sliced into $1 \mathrm{~cm}$ interval from surface to bottom were collected in each lake. All sediment samples were packed in aluminum foil and transported on ice to the laboratory, where they were stored at $-20^{\circ} \mathrm{C}$ until further treatment. In this study, 16 US EPA priority PAHs were determined: naphthalene (Nap), acenaphthylene (Acey), acenaphthene (Ace), fluorene (Flu), phenanthrene (Phe), anthracene (Ant), fluoranthene (Fla), pyrene (Pyr), chrysene (Chr), benzo[a]anthracene (BaA), benzo[b]fluoranthene $(\mathrm{BbF})$, benzo[k]fluoranthene $(\mathrm{BkF})$, benzo[a]pyrene (BaP), indeno[1,2,3-cd]pyrene (IcdP), dibenzo$[\mathrm{a}, \mathrm{h}]$ anthracene $(\mathrm{DahA})$ and benzo[g,h,i]pyrene (BghiP).

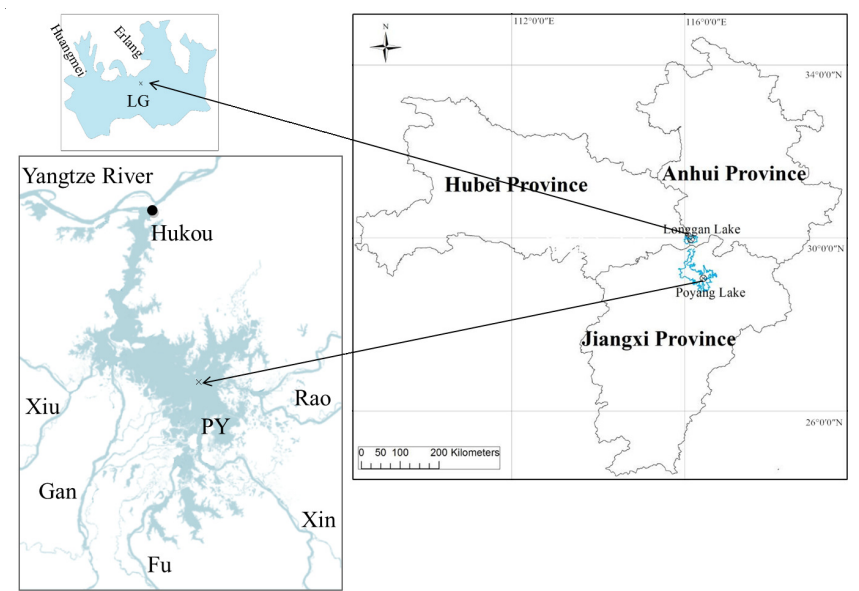

Fig. 1. Map of sampling sites in Poyang lake and Longgan lake

A composite standard solution of sixteen PAHs was purchased from AccuStandard Chem. Co. (USA). The solvents (acetone, $n$-hexane and dichloromethane) used for sample processing and analysis was of pesticide residue analysis grade and distilled with a full glass unit. The glassware and glass pipettes were initially rinsed with de-ionized water, which was produced by a Milli-Q system (Millipore Co., USA). Analytical grade anhydrous sodium sulfate, activated silica gel and neutral alumina were also used.

PAHs analysis: The sediment samples were extracted by Soxhlet extraction technique with $100 \mathrm{~mL}$ dichloromethane for $48 \mathrm{~h}$. To estimate the recovery rate of the pretreatment procedure, naphthalene-D8, phenanthrene-D10, pyrene-D10 and Chrysene-D12 were added to test tubes before extraction. Then extracts were eluted through a chromatographic column packed with sodium sulfate, aluminium oxide and deactivated silica gel in $n$-hexane/dichloromethane (1:1, v/v) solution and eventually concentrated to $1 \mathrm{~mL}$ under gentle nitrogen flow. Hexamethyl benzene ( $200 \mathrm{ng}$ )was spiked as an internal standard for further analysis.
Determination of sixteen priority PAHs was performed on gas chromatography-mass spectrometry (GC-MS) using GCMSQP 2010 with a DB-5MS capillary column $(30 \mathrm{~m} \times 0.25 \mathrm{~mm}$, i.d., $0.25 \mu \mathrm{m}$ film thickness). The injection, interface and the ion source temperature were maintained at 295,290 and $220^{\circ} \mathrm{C}$, respectively. The column oven temperature program was initiated at $70{ }^{\circ} \mathrm{C}$ for $2.0 \mathrm{~min}$, increased to $295^{\circ} \mathrm{C}$ at a rate of $3{ }^{\circ} \mathrm{C} / \mathrm{min}$ and finally held for $5 \mathrm{~min}$. The flow rate of the carrier gas helium was kept constant at $1.2 \mathrm{~mL} / \mathrm{min}$. Identification of PAHs was based on the selected ions monitoring (SIM) mode.

In order to control quality, a blank experiment was necessary. Quantification was performed using the internal calibration method based on five-point calibration curves for individual compounds. The $\mathrm{R}^{2}$ values of sixteen PAHs were in the range of 0.9849-0.9999 and extraction recoveries were in the range 80-100\%.

Dating of sediment cores: The dating of the sediment cores from Poyang lake and Longgan lake was calculated by means of ${ }^{137} \mathrm{Cs}$ and ${ }^{210} \mathrm{~Pb}$ dating techniques [11]. ${ }^{226} \mathrm{Ra}$ and ${ }^{210} \mathrm{~Pb}$ were determined by $\lambda$-rays emitted at 352 and $46.5 \mathrm{keV}$, respectively.

\section{RESULTS AND DISCUSSION}

Distribution of PAHs Concentrations: In this study, sixteen US EPA priority PAHs in soil samples from Poyang and Longgan lakes were measured after sampling. Only six PAHs (FLU, PHE, FLA, BaA, BbF and BkF) were detected at all the samples of Core Longgan lake, while in Core Poyang lake, fourteen PAHs except for NAP and PHE were found. The PAHs compositions were dominated by 2-3 ring PAHs with a mean of $50 \%$ in Core Poyang lake and $56 \%$ in Core Longgan lake, followed by 5-6 ring PAHs compositions. The 4-ring PAHs were the least abundant, averaging only $17 \%$ in Core Poyang lake and $14 \%$ in Core Longgan lake. The predominant PAHs in Poyang lake and Longgan lake were consistent with the findings of other lakes in China [12,13], although there were huge disparities in the total PAHs concentrations of different lakes.

The individual concentrations of 16 PAHs in the surface sediment samples (0-2 cm) ranged from 4.7 to $282 \mathrm{ng} / \mathrm{g}$ in Core Poyang lake and from 1.4 to $281 \mathrm{ng} / \mathrm{g}$ in Core Longgan lake. The mean concentrations of sixteen PAHs in surface sediments were $740 \mathrm{ng} / \mathrm{g}$ and $241 \mathrm{ng} / \mathrm{g}$ in Core Poyang and Longgan lakes. A comparison of PAHs concentrations in surface sediments between the other rivers and lakes in the world and Poyang and Longgan lakes is shown in Table-1. The PAHs pollution levels in Poyang and Longgan lakes were in the middle and low levels, respectively.

TABLE-1

COMPARISON OF $\Sigma$ PAH CONCENTRATIONS IN SURFACE SEDIMENTS FROM DIFFERENT LOCATIONS

\begin{tabular}{lcc}
\hline \multicolumn{1}{c}{ Location } & $\begin{array}{c}\text { Mean concentration } \\
\text { (ng/g dry weight) }\end{array}$ & References \\
\hline Yangtze Estuary, China & 221.18 & {$[6]$} \\
Longgan lake, China & 241 & This study \\
Zhanjiang Bay, China & 316 & {$[14]$} \\
Poyang lake, China & 740 & This study \\
Daliao estuary, China & 743.03 & {$[15]$} \\
Narragansett Bay, USA & 21100 & {$[16]$} \\
Izmit Bay, Marmara Sea & $6.01 \times 10^{5}$ & {$[17]$} \\
\hline
\end{tabular}


Historical trends of $\Sigma$ PAHs concentrations in sediment cores: The total concentrations of sixteen priority PAHs varied from 70 to $6855 \mathrm{ng} / \mathrm{g}$ (mean = $227 \mathrm{ng} / \mathrm{g}$ ) and from 60 to 231744 $\mathrm{ng} / \mathrm{g}($ mean $=185 \mathrm{ng} / \mathrm{g}$ ) in Cores Poyang and Longgan lakes, respectively. The highest concentrations of $\Sigma$ PAHs appeared in Core Poyang lake, could be ascribed to the population densities. With plentiful ecological resources and earlier exploitation, Poyang lake has an estimated population of 8 million, roughly 400 times as many as that in Longgan lake.

Many studies have demonstrated the practicability of a diagnostic ratio based on differences of thermodynamic stabi-

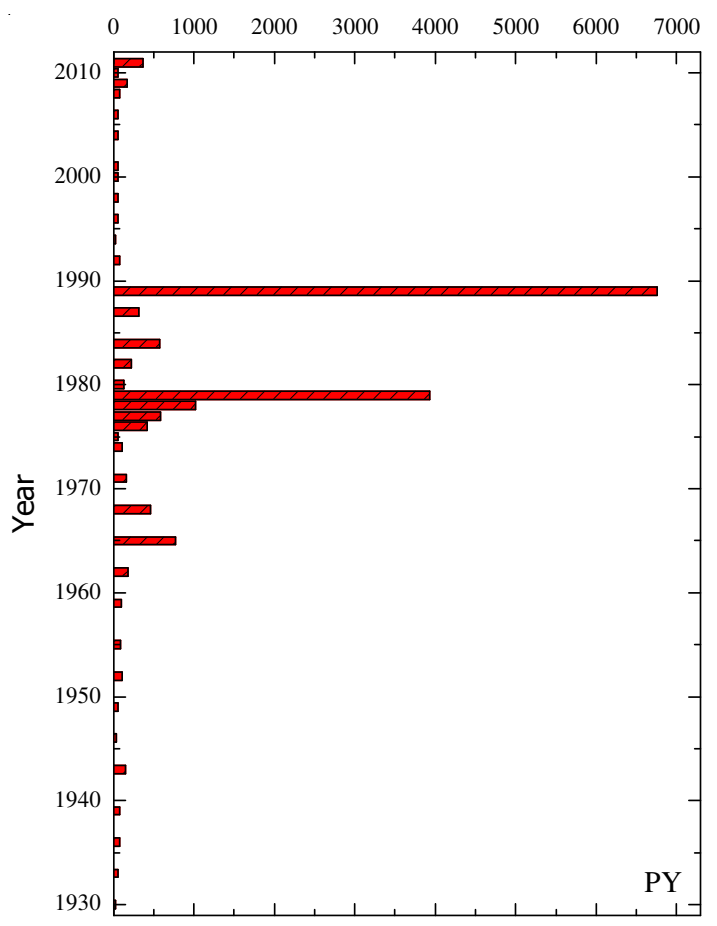

lities between isomers of the same molecular mass in source apportionment [18]. The vertical distribution of 2-3 ring (low molecular weight, LMW) PAHs, 4-6 ring (high molecular weight, HMW) PAHs and $\Sigma$ PAHs concentrations in two sediment cores are reflected in Fig. 2. By and large, in Core Poyang lake, the $\Sigma$ PAHs concentrations increased between approximately 1930 and 1979 (70 ng/g to $4028 \mathrm{ng} / \mathrm{g}$ ), decreased and then increased significantly to $6855 \mathrm{ng} / \mathrm{g}$ in 1989. After 1989, इPAHs concentrations reduced again and the maximum were observed in 2011 (629 ng/g). Similar historical changes could be found in 2-3 ring PAHs

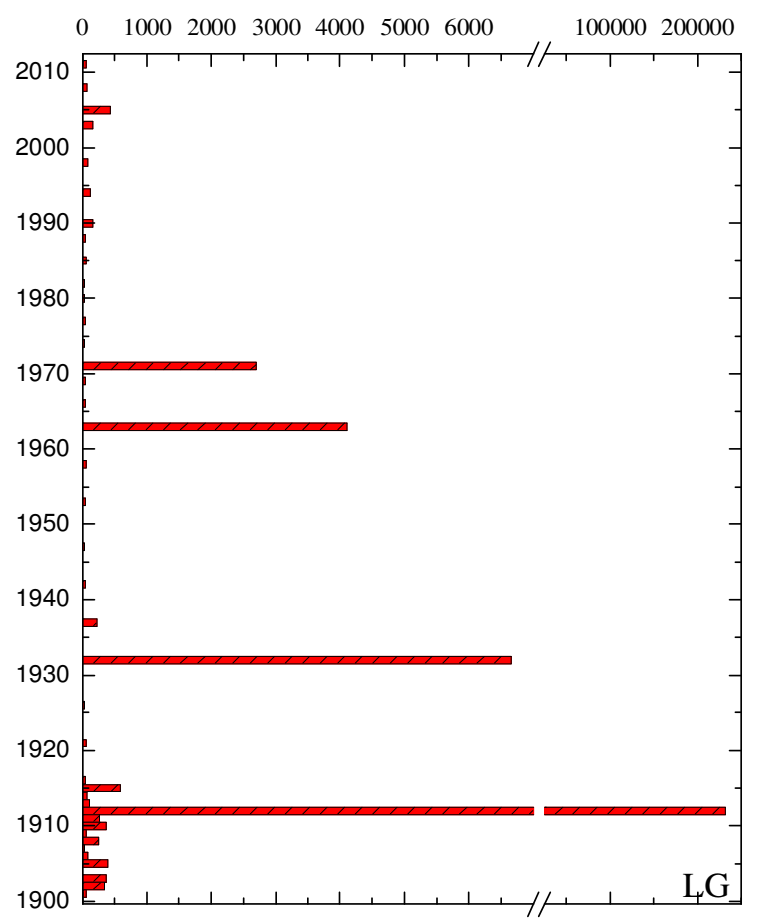

(a) Concentrations of 2-3 ring polynuclear aromatic hydrocarbons ( $\mathrm{gg} / \mathrm{g}$ dry weight)
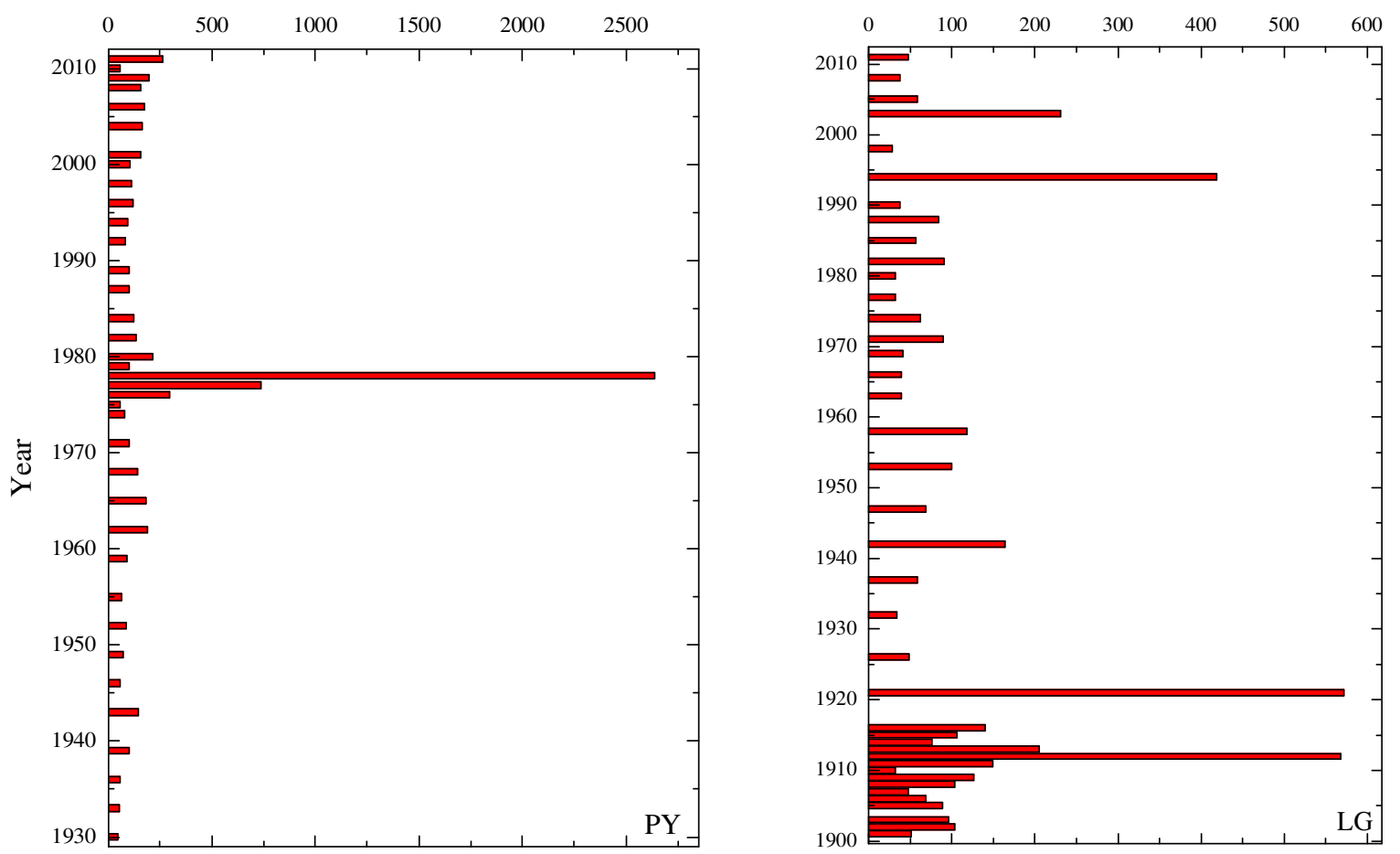

(b) Concentrations of 4-6 ring polynuclear aromatic hydrocarbons ( $\mathrm{ng} / \mathrm{g}$ dry weight) 

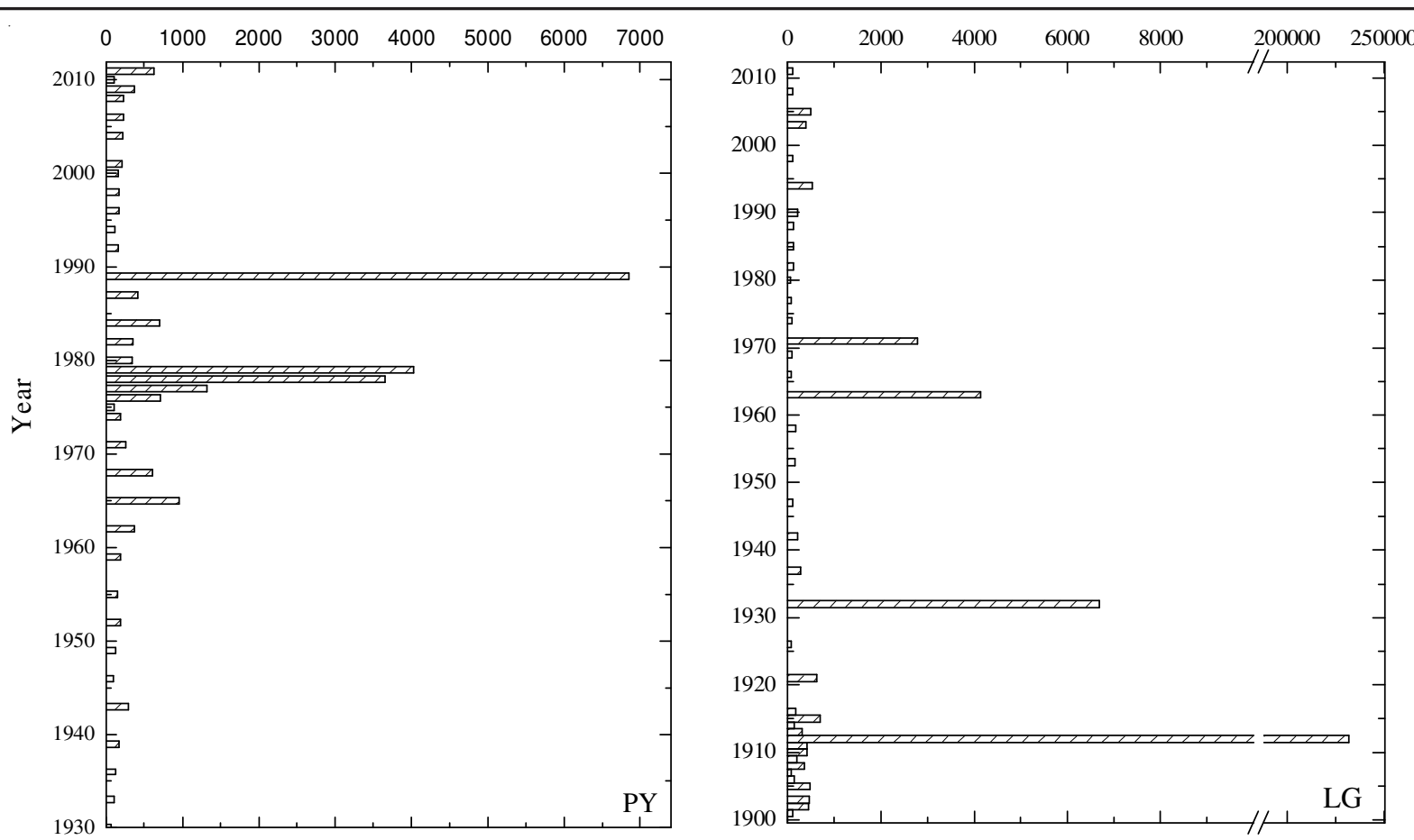

(c) Concentrations of sum of polynuclear aromatic hydrocarbons ( $\mathrm{ng} / \mathrm{g}$ dry weight)

Fig. 2. Historical trends of the $\Sigma$ PAHs concentrations (ng/g dry weight)

concentrations in the past decades while the concentrations of 4-6 ring PAHs were relatively constant except for a peak value occurred in 1978. Core Longgan lake showed that between 1901 and 2011 there were four peaks in sedimentary samples and they appeared, respectively in 1912 (231744 ng/g), 1932 (6693 ng/g), 1963 (4145 ng/g) and $1971(2789 \mathrm{ng} / \mathrm{g})$. In general, the $\Sigma$ PAHs concentrations in Core Longgan lake decreased from the deep layer to the surface, which is different from those in Core Poyang lake. The variation in 2-3 ring PAHs concentrations had the same varying trend as $\Sigma \mathrm{PAHs}$ concentrations in Core Longgan lake.

Source apportionment of PAHs: Diagnostic ratios have been most widely applied to identify the emission sources of PAHs, e.g., incomplete combustion of organic materials (domestic heating), unburned petroleum (oil discharge) and combustion of liquid fossil fuel (traffic emission). Based on the stability, PAHs fall into two subsets: less stable PAHs which are formed during combustion process; more thermodynamically stable PAHs. Since different PAHs sources may provide specific patterns or signatures from the relative ratio of a given molecular mass, the possible contribution of PAHs may be identified [19-21].

In the present study, the presence of PAHs in sediment samples with a ratio of FLA/(FLA + PYR $)<0.4$ indicates petroleum input. The ratio which is between 0.4 and 0.5 implies liquid fossil fuel combustion input and ratios exceeding 0.5 are attributed to grass, wood or coal combustion input [21]. In Core Poyang lake, the ratio of FLA/(FLA + PYR) was 0.51 to 0.65 (> 0.50, Fig. 3 (a)) over the period from 1930 to 2011, reflecting more direct effect of $\mathrm{PAH}$ emission by the predominance of pyrogenic sources, mostly grass combustion $(0.58 \pm 0.04)$ and wood combustion $(0.51 \pm 0.06)$. The main reason for this phenomenon is that local farmers usually burn grasses for new growth to feed on cattle. Maximum ratio (0.65) was observed in approximately 2009, which was associated with the frequent fire accidents due to the increasingly number of sand exca-vation activities. In Core Longgan lake, the ratios of FLA/(FLA+PYR) between 1901 and 2011 ranging from 0.50 to 0.75 were all higher than 0.5 , which could be identified as the biomass and domestic coal combustion source. Similarly, grass and wood combustions were the two predominant contributions. Three peak ratios which occurred around 1902, 1911 and 1921, respec-tively, may have something to do with fire events.

The Ind/(Ind + BghiP) ratio can also offer useful information for distinguishing the PAHs origins [20]. Sediment with Ind/(Ind + BghiP $)<0.2$ are consistent with petroleum source, while Ind/(Ind + BghiP) $>0.5$ are typical type of combustion origins and intermediate ratios $(0.20-0.50)$ indicate mixed origins. The Ind/(Ind + BghiP) ratios were in the range of 0.500.59 and $0.51-0.50$ in Core Poyang lake and Core Longgan lake, respectively, clearly indicating pyrogenic sources $(>0.5$, Fig. 3(b)) and supporting the interpretation of the FLA/(FLA + PYR) ratios.

PAHs with molecular weight of 228 (chrysene and benzo[a]anthracene), which are usually minor components in refined petroleum products but present in great amounts in higher boiling point fractions, are used less frequently as indicators of contaminant sources [22,23]. Yunker et al. [21] used the ratio of $\mathrm{BaA} / \mathrm{CHR}$ to identify combustion sources $(>0.35)$, a mixture of combustion and petroleum sources $(0.20-0.35)$ and petroleum sources $(<0.20)$. In Core Poyang lake, the period between 1930 and 1943 with the ratios of BaA/CHR higher than 0.35 (0.42-0.48, Fig. 3(c)), can be most likely attributed to wood combustion (0.40-0.52) and grass combustion (0.420.52 ). From 1943 to 1952 , this ratio decreased progressively to 0.31 indicating the influence of kerosene combustion $(0.30$ 0.44 ) on account of expanding fisheries. In the period from 


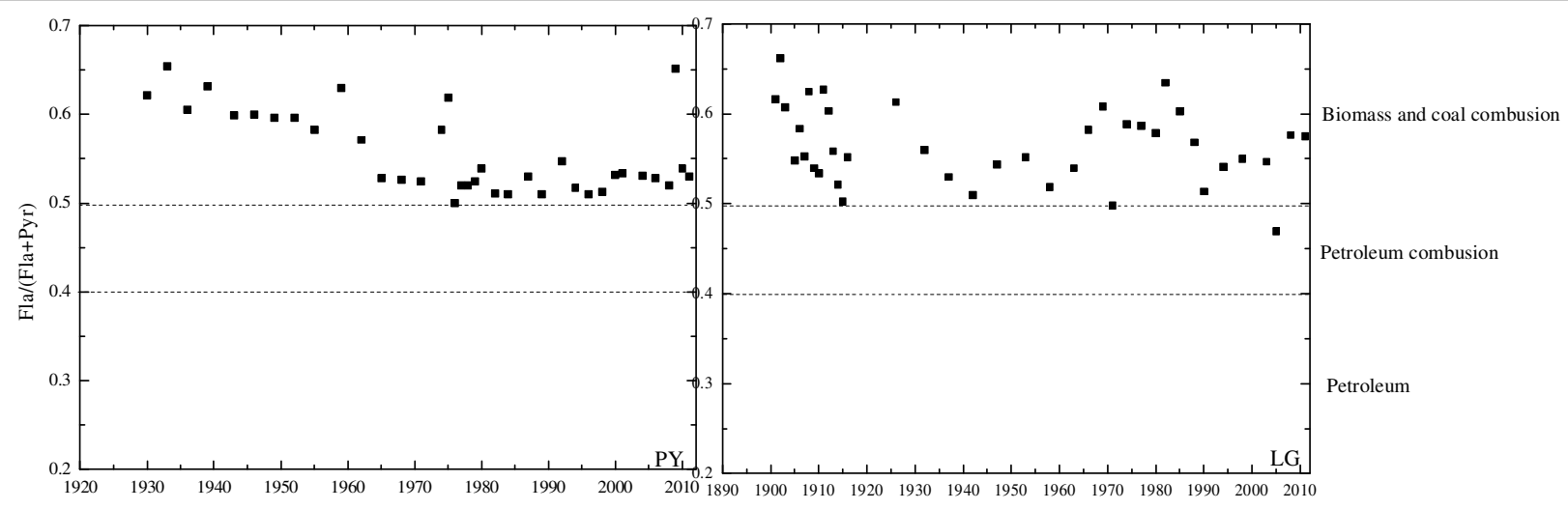

Year

(a) FLA/(FLA + PYR)
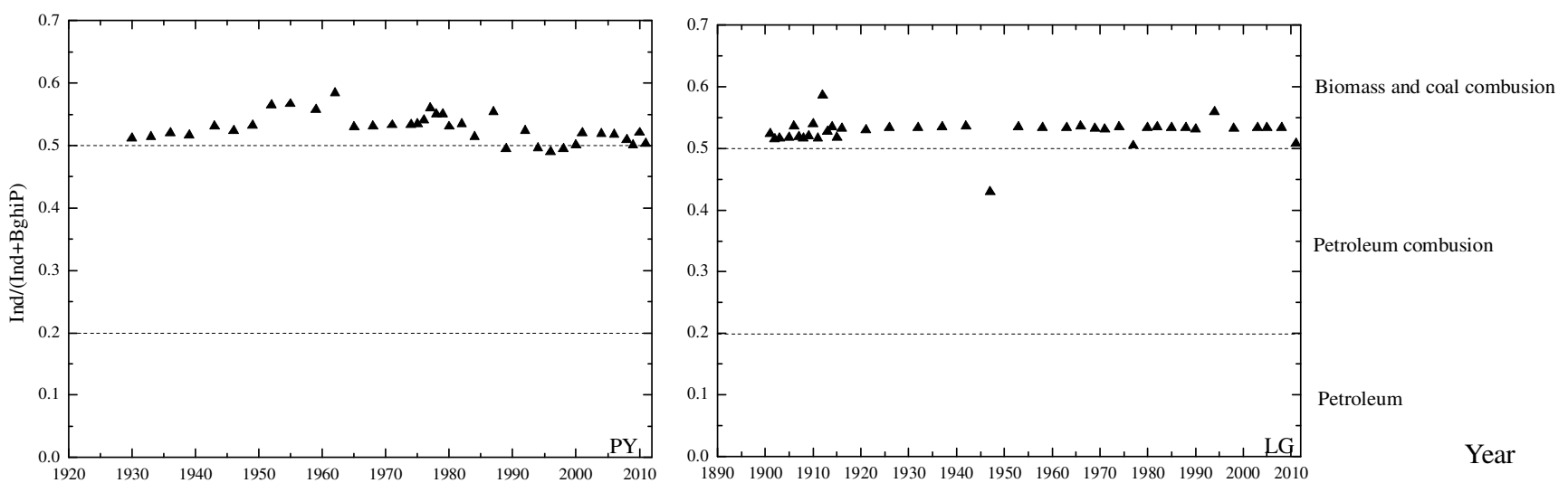

(b) $\operatorname{Ind} /($ Ind+BghiP)
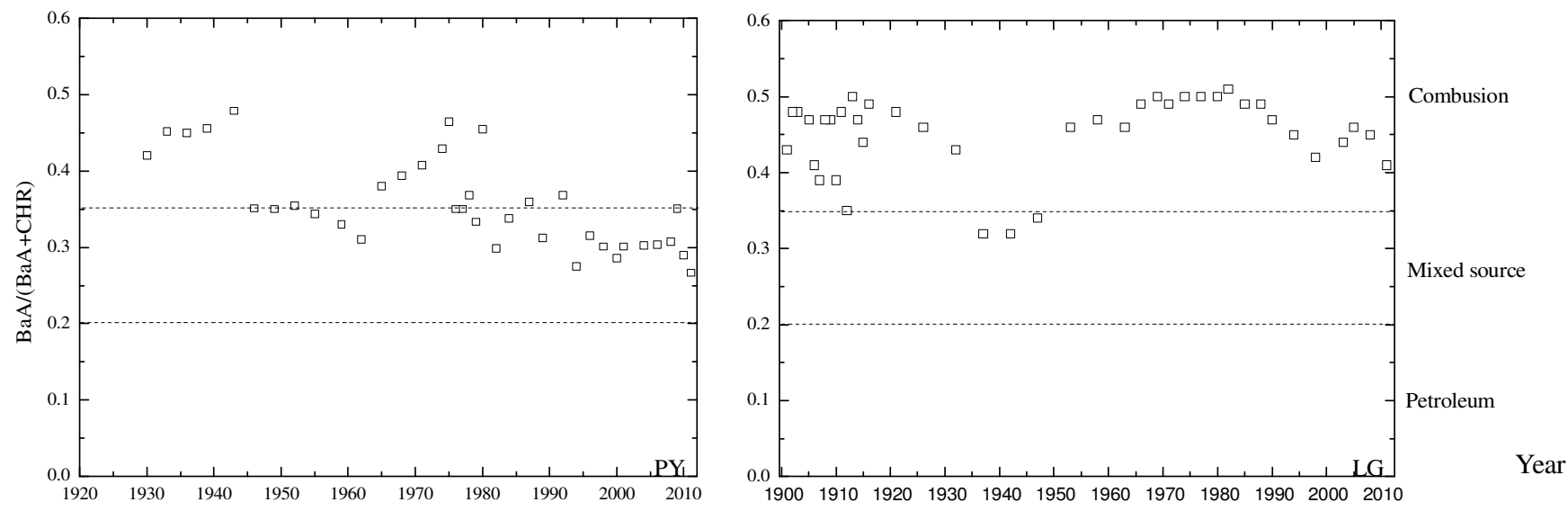

(c) $\mathrm{BaA} / \mathrm{CHR}$

Fig. 3 Polynuclear aromatic hydrocarbons ratios for cores over time

1952 to 1976 , an obvious increase in the BaA/CHR ratios could be ascribed to grass burning to feed cattle by local people. After 1976, the BaA/CHR ratios showed a downward trend, sugges-ting the same sources as diesel combustion $(0.38 \pm$ $0.01)$, fuel oil combustion $(0.17 \pm 0.05)$ and contamination by petroleum sources such as diesel oil $(0.35 \pm 0.04)$ and kerosene (0.35) may reduce the ratios through to present day. In this period, with the development of economy and prosperity of the tourism, the number of tourist buses and ships is booming. In Core Longgan lake, the $\mathrm{BaA} / \mathrm{CHR}$ ratios all of which exceeded 0.35 with a tight range from 1901 to 1932 may be related to the plant combus-tion (i.e. forest fires). A small fall in the ratios between 1932 and 1950 can be attributed to kerosene combustion (0.30-0.44) due to the increased number of fishing boats. The ratios went up which were associated with cattle rearing like Poyang lake district from 1950 to 1982. The peak (in approximately 1982) indicated the additional influence of creosote $(0.50 \pm 0.03)$. After 1982, a slight decrease in the $\mathrm{BaA} / \mathrm{CHR}$ ratios enjoyed the same reason as Core Poyang lake over the period from 1976 to present.

In general, all ratios analyzed displayed that wood and grass combustion were the two leading sources both in Core Poyang and Longgan lakes. From the BaA/CHR ratios, the period from 1943 to 1976 in Core Poyang lake and from 1932 
to 1982 in Core Longgan lake, may be a transition period, along with a mixture of biomass and petro-leum combustion sources. Finally, the impact of petroleum combustion and petroleum contamination has become more significant after 1976 in Core Poyang lake and after 1982 in Core Longgan lake.

Risk assessment: As an effective index to assess the potential toxicity of PAHs, the BaP equivalent (BaPE) can be calculated according to the following equation $[13,24,25]$ :

$$
\begin{aligned}
\mathrm{BaPE}= & \mathrm{BaA} \times 0.06+\mathrm{BbF} \times 0.07+\mathrm{BkF} \times 0.07+ \\
& \mathrm{BaP}+\mathrm{DahA} \times 0.60+\mathrm{IcdP} \times 0.08
\end{aligned}
$$

The calculated BaPE values in this study were illustrated in Fig. 4. It is shown that BaPE values varied from 7.6 to 187 ng/g dw (mean: $26 \mathrm{ng} / \mathrm{g} \mathrm{dw}$ ) in Core Poyang lake and from 5.4 to $107 \mathrm{ng} / \mathrm{g} \mathrm{dw}$ (mean: $22 \mathrm{ng} / \mathrm{g} \mathrm{dw}$ ) in Core Longgan lake. Higher BaPE values were found at Poyang lake. The phenomenon that historical trends of the $\mathrm{BaPE}$ values in both lakes were consistent with the $\Sigma$ PAHs vertical concentrations implies that higher $\Sigma$ PAHs concentrations were corresponded to greater toxicities.

Toxic equivalency factors (TEFs) of seven carcinogenic PAHs (including BaA, Chr, BbF, BkF, BaP, DahA and IcdP), is another method to quantitatively assess the potential toxicological significance to human health. The TEFs for BaA, Chr, BbF, BkF, BaP, DahA and IcdP are 0.001, 0.1, 0.1, 0.1, 1, 0.1 and 1, respectively according to the US EPA [12]. The overall toxic equivalents (TEQs) are defined by the following equation: TEQs $=\Sigma C_{i} \times T_{E F}$, where $C_{i}$ is the concentration of individual $\mathrm{PAH}$ and $\mathrm{TEF}_{\mathrm{i}}$ is the corresponding TEF. The TEQs in the two core sediments were in the range of 9.9-248 ng/g in Core Poyang lake and 5.9-132 ng/g in Core Longgan lake,

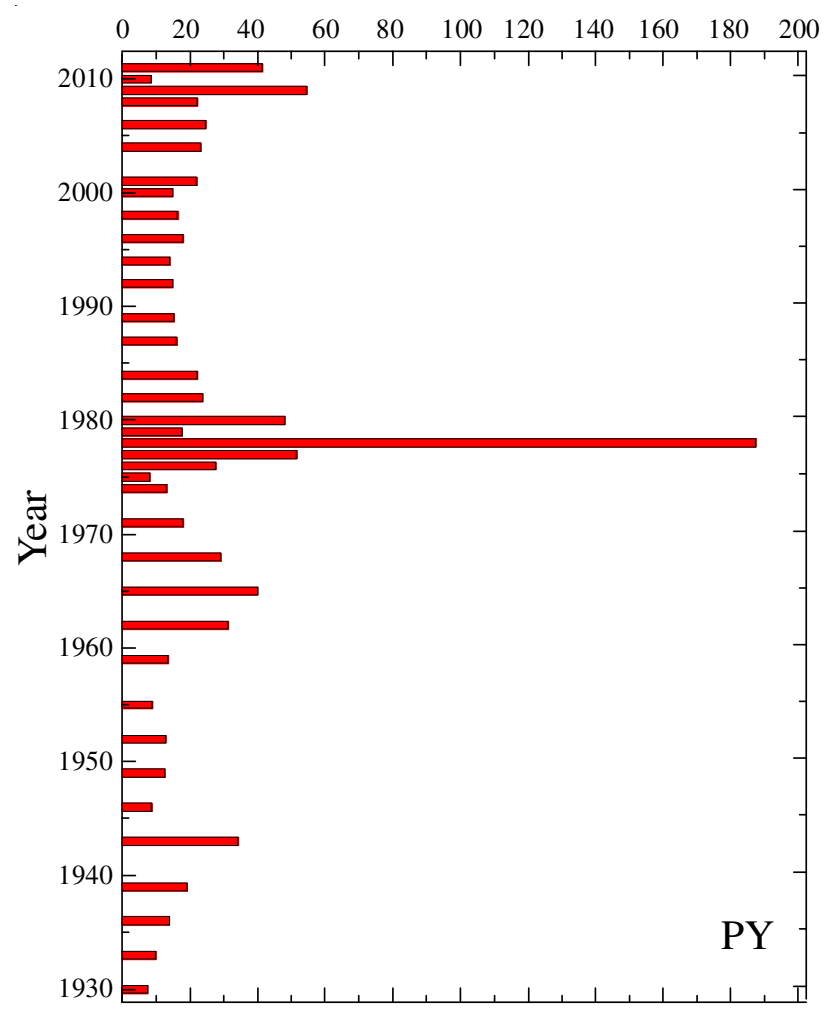

both of which were lower than the reported sediment cores in Hongfeng lake (94-856 ng/g) in China [12]. But the TEQs in Core Poyang lake were a little higher than sediment cores in the harbor of Naples $(21-220 \mathrm{ng} / \mathrm{g})$ in Italy [26]. In the two core sediments, BaP, DahA and BbF were the dominant toxic compositions, accounting for $90.0 \pm 8.1 \%$ in Core Poyang lake and $86.2 \pm 3.4 \%$ in Core Longgan lake. BaP which contributed the maximum carcinogenic exposure equivalent was the most hazardous, followed by DahA and BbF. The percen-tage of BaP, DahA and BbF in TEQs varied from 39 to $72 \%, 18$ to $46 \%$ and 3.0 to $7.7 \%$ in Core Poyang lake, from 42 to $49 \%, 27$ to $45 \%$ and 1.6 to $8.8 \%$ in Core Longgan lake, respectively. This fact underlined the necessity to be in control of these seven carcinogenic PAHs in future years and more effective management should be carried out in the context of large PAHs emission in China.

\section{Conclusion}

The levels of PAHs pollution in Poyang lake and Longgan lake during the last 71 and 100 years, respectively were assessed by analyzing PAHs historical distribution as well as isomer ratios. The PAHs compositions were dominated by 2-3 ring PAHs both in Core Poyang lake and in Core Longgan lake, which were consis-tent with the result of other lakes in China. Maximal SPAHs concentrations appeared in Core Poyang lake compared with Core Longgan lake, which could be ascribed to its higher population densities. Different from Core Poyang lake, the $\Sigma$ PAHs concentrations in Core Longgan lake decreased from the deep layer to the surface.

The PAHs isomer ratios were applied for PAHs sources identification. FLA/(FLA + PYR) and Ind/(Ind + BghiP) ratios showed that wood and grass combustion was the two leading

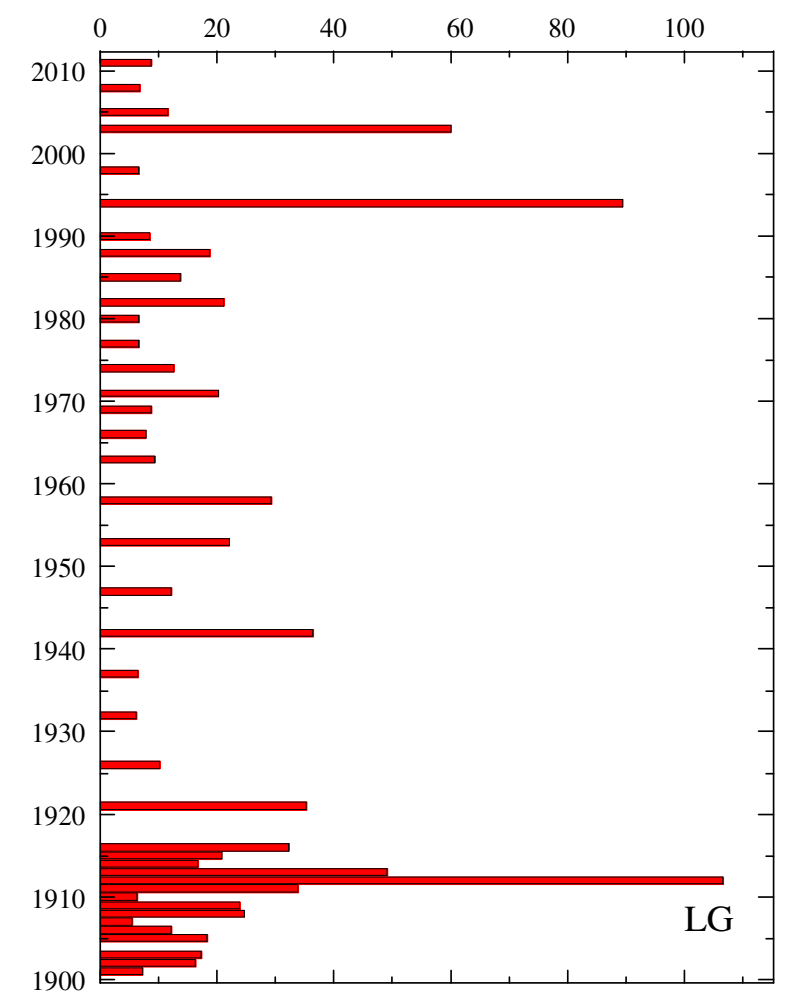

Fig. 4. Historical trends of $\mathrm{BaPE}$ values (ng/g dry weight) 
sources both in Core Poyang and Longgan lakes. From the $\mathrm{BaA} / \mathrm{CHR}$ ratios, the period from 1943 to 1976 in Core Poyang lake and from 1932 to 1982 in Core Longgan lake, may be a transition period, along with a mixture of biomass and petroleum combustion sources. This phenomenon could be ascribed to grass burning to feed cattle by local people. Finally, the impact of petroleum combustion and petroleum contamination has become more significant after 1976 in Core Poyang lake and after 1982 in Core Longgan lake because with the development of economy and prosperity of the tourism, the number of tourist buses and ships is booming.

The toxicological risk evolutions based on BaPE and TEQs values indicated that Poyang lake suffered greater toxicities than Longgan lake. The BaP, DahA and BbF were the dominant toxic compositions and $\mathrm{BaP}$, which contributed the maximum carcinogenic exposure equivalent was the most hazardous in both two core sediments.

Results presented in this study have provided insight into the historical input of polycyclic aromatic hydrocarbons (PAHs) and indicate an anthropogenic environmental influence in Poyang lake and Longgan lake, which are economically significant regions in China due to their rich ecological resources.

\section{ACKNOWLEDGEMENTS}

This work was supported by the National Natural Science Foundation of China (No.: 51379223).

\section{REFERENCES}

1. L. Culotta, C.D. Stefano, A. Gianguzza, M.R. Mannino and S. Orecchio, Mar. Chem., 99, 117 (2006);

https://doi.org/10.1016/i.marchem.2005.05.010.

2. M. Qiao, C.X. Wang, S.B. Huang, D.H. Wang and Z.J. Wang, Environ. Int., 32, 28 (2006);

https://doi.org/10.1016/j.envint.2005.04.005.

3. U.M. Sofowote, B.E. Mccarry and C.H. Marvin, Environ. Sci. Technol., 42, 6007 (2008); https://doi.org/10.1021/es800219z.

4. H.S. Wang, Z. Cheng., P. Liang., D.D. Shao, Y. Kang. S.C. Wu, C.K.C. Wong and M.H. Wong, Ecotoxicol. Environ. Saf., 73, 900 (2010); https://doi.org/10.1016/j.ecoenv.2010.04.010.

5. E.R. Christensen and S. Arora, Water Res., 41, 168 (2007); https://doi.org/10.1016/j.watres.2006.09.009.

6. B.H. Li, C.H. Feng, X. Li, Y.X. Chen, J.F. Niu and Z.Y. Shen, Mar. Pollut. Bull., 64, 636 (2012);

https://doi.org/10.1016/j.marpolbul.2011.12.005.

7. Z.G. Guo, T. Lin, G. Zhang, M. Zheng, Z.Y. Zhang, Y.C. Hao and M. Fang, Sci. Total Environ., 386, 33 (2007); https://doi.org/10.1016/j.scitotenv.2007.07.019.

8. A.O. Barakat, A. Mostafa, T.L. Wade, S.T. Sweet and N.B.E. Sayed, Water, Air, Soil Pollut., 218, 63 (2011); https://doi.org/10.1007/s11270-010-0624-5.
9. J.Y. Guo, F.C. Wu, X.J. Luo, Z. Liang, H.Q. Liao, R.Y Zhang, W. Li, X.L. Zhao, S.J. Chen and B.X. Mai, Environ. Pollut., 158, 2175 (2010); https://doi.org/10.1016/j.envpol.2010.02.018.

10. R. Zhang, F. Zhang and T.C. Zhang, Sci. Total Environ., 450-451, 280 (2013); https://doi.org/10.1016/j.scitotenv.2013.02.029.

11. A.C. Ruiz-Fernández, F. Páez-Osuna, J. Urrutia-Fucugauchi, M. Preda and I. Rehault, J. Environ. Monit, 6, 473 (2004); https://doi.org/10.1039/B316583C.

12. J.Y. Guo, F.C. Wu, L. Zhang L, H.Q. Liao, R.Y. Zhang, W. Li, X.L. Zhao, S.J. Chen and B.X. Mai, Arch. Environ. Contam. Toxicol., 60, 590 (2011); https://doi.org/10.1007/s00244-010-9568-4.

13. W.X. Liu, H. Dou, Z.C. Wei, B. Chang, W.X. Qiu, Y. Liu and S. Tao, Sci. Total Environ., 407, 1436 (2009); https://doi.org/10.1016/j.scitotenv.2008.10.055.

14. W.X. Huang, Z.Y. Wang Z and W. Yan, Mar. Pollut. Bull., 64, 1962 (2012); https://doi.org/10.1016/j.marpolbul.2012.05.023.

15. B. Men, M.C. He, T. Li, C.Y. Lin and X.C. Quan, Mar. Pollut. Bull., 58, 818 (2009); https://doi.org/10.1016/i.marpolbul.2009.01.022.

16. P.C. Hartmann, J.G. Quinn, R.W. Cairns and J.W. King, Mar. Pollut. Bull., 48, 351 (2004);

https://doi.org/10.1016/j.marpolbul.2003.08.014.

17. F. Telli-Karakoç, L. Tolun, B. Henkelmann, C. Klimm, O. Okay and K.W. Schramm, Environ. Pollut., 119, 383 (2002); https://doi.org/10.1016/S0269-7491(01)00341-4.

18. H.M. Yuan, T.G. Li, X.G. Ding, G.M. Zhao and S.Y. Ye, Mar. Pollut. Bull., 83, 258 (2014); https://doi.org/10.1016/j.marpolbul.2014.03.043.

19. G.Q. Liu, G. Zhang, X.D. Li, J. Li, X.Z Peng and S.H. Qi, Mar. Pollut. Bull., 51, 912 (2005); https://doi.org/10.1016/j.marpolbul.2005.02.038.

20. M.B. Yunker, R.W. Macdonald, D. Goyette, D.W. Paton, B.R. Fowler, D. Sullivan and J. Boyd, Sci. Total Environ., 225, 181 (1999); https://doi.org/10.1016/S0048-9697(98)00362-3.

21. M.B. Yunker, R.W. Macdonald, R. Vingarzan, R.H. Mitchell, D. Goyette and S. Sylvestre, Org. Geochem., 33, 489 (2002); https://doi.org/10.1016/S0146-6380(02)00002-5.

22. A. Gogou, I. Bouloubassi and E.G. Stephanou, Mar. Chem., 68, 265 (2000); https://doi.org/10.1016/S0304-4203(99)00082-1.

23. J.W. Readman, R.F.C. Mantoura and M.M. Rhead. Sci. Total Environ., 66, 73 (1987); https://doi.org/10.1016/0048-9697(87)90079-9.

24. Y. Zhang, C.S. Guo, J. Xu, Y.Z. Tian, G.L. Shi and Y.C. Feng, Water Res., 46, 3065 (2012); https://doi.org/10.1016/j.watres.2012.03.006.

25. L.L.Wang, Z.F. Yang, J.F. Niu and J.Y. Wang, J. Hazard. Mater, 169 , 460 (2009); https://doi.org/10.1016/j.jhazmat.2009.03.125

26. M.L. Feo, M. Sprovieri, S. Gherardi, S. Sammartino and E. Marsella, Environ. Monit. Assess., 174, 445 (2011); http://doi.org/10.1007/s10661-010-1469-5. 